\title{
Architecture Energy-saving Design Guided by Low Carbon Concept
}

\author{
Wei Chen \\ Institute of Art \& Design, Nanchang Hangkong University, Nanchang, China
}

\begin{abstract}
Low carbon and energy saving are the key factors influencing on the sustainable development of architectural industry. In the modern society featuring increasingly energy shortage and advocacy on low-carbon lifestyle, architectural designers shall take effective methods in architectural energysaving design to upgrade the energy-saving level of architectures, reduce energy consumption and realize the law carbon in architecture construction and operation. This paper introduces the related problems to be noticed in architecture energy-saving design and proposes certain concrete measures and methods in architecture energy-saving design, expecting to provide with certain reference for architecture energy-saving design.
\end{abstract} design

Keywords-low carbon; architecture energy saving; architecture

\section{INTRODUCTION}

Currently, the world is undergoing a phase of rapid development, along with the accelerated urbanization development lasting for a while; however, architecture industry, as the important one in urban development, has been facing with the prominent energy issues. It has been the emphasis of architecture energy-saving design today to find the ways to use energies more effectively and how to upgrade the energy-using efficiency of architectures, in order to guide the low-carbon lifestyle and realize the overall energy-saving of architectures. Architecture energy-saving, through selecting energy-saving design and measures, energy-saving and environmental-protection materials and energy-saving operation and management methods, aims at creating sound economic benefit and artificial architecture environment for human beings[1]. Designers must understand the problems they shall pay great attention to in architecture energy-saving design and master the effective ideas of architecture energysaving design.

\section{Attentive Problems in ARChitecture EnERgY-SAVING DESIGN}

Architecture energy-saving designers shall be aware that the energy-saving design runs through the entire process from architecture design planning to post-stage architecture operation. Therefore, designers shall inject the low-carbon concept since the beginning of architecture planning; follow the strategy of using natural and reproducible energies, in order to upgrade the use efficiency of natural reproducible energies and reduce the consumption of various artificial energies. Such a design concept can lay a solid foundation for the effective implementation of high energy saving, low carbon consumption and low emission at the later stage of architecture operation. Therefore, designers shall consider and solve the energy-saving-related problems at the architecture planning stage, to lay the first stone for the subsequent energysaving design of architecture projects.

\section{A. Initiative Energy-saving Awareness at Architecture Design Planning Stage}

In the past, the energy-saving concept guided by low carbon was hardly introduced in architecture design planning. Along with the increasingly prominent energy shortage problem, the energy-saving policy for low carbon consumption has become one of the core problems in architecture design. In order to reduce the high energy consumption of architectures, architecture design advocates to pay attention to energy-saving design since the stage of architecture planning now, in order to plan architecture scale, direction and relationship with other architectures in the way of energy saving and low carbon, though comprehensive consideration of factors including lighting, ventilation, warmkeeping and heat preservation, to apply natural wind energy, light energy and other environmental-friendly energies as much as possible to reduce energy consumption in architecture operation. For instance, some cities in southern China suffer from hot and scorching weather with long sunshine duration and high humidity. Therefore, designers shall take full consideration of orientation and spacing of architectures at the stage of architecture layout, in order to lay out architectures in north-south direction and reduce the heat generated by sunshine radiation; and increase the spacing between architectures for air motion and temperature reduction to reduce the use of air conditioners and other refrigeration equipments and energy consumption. All of those measures are to the benefit of utilizing natural principles to solve energy consumption problems. However, the methods that realize energy saving and emission reduction through changing the natures of architectures shall be taken into full consideration at the beginning of architecture design, for planned architecture energy-saving planning based on local conditions.

\section{B. Concrete Architecture Design Phase Guided by Low Carbon and Energy Saving}

Concrete architecture design focuses on researching parameters related to architecture energy saving, in order to reduce high energy-consumption materials and apply new materials and techniques under the guiding ideology of low carbon and energy saving, based on the following aspects. Firstly, designers shall concern the energy consumption distribution of different areas and spaces; apply related materials rationally; and use related energy-saving 
technologies and equipments for accurate planning. For instance, the energy consumptions in public areas and residential areas are different; moreover, the form of energy consumption in public areas is more complicated with multiple modes, requiring the designers to fully consider those factors and focus on energy saving in public areas with high energy consumption. Secondly, designers shall consider whether the architecture plan can use the natural reproductive energies to the maximum level, and this is the development director for modern architecture energy-saving design. Generally speaking, the conveniently natural productive energies in architectures are solar power and wind power. Architecture design plans shall create beneficial conditions for natural reproductive energies; seek for the optimal design plans to promote the use efficiency; save the consumption of normal energies; and reduce the emission of wastes. For instance, modern architecture designs add composite materials into walls, which can absorb the heat generated by sunshine to maintain the indoor temperature at a relatively constant level.

\section{Considering Adaptability of Architectural form and Environment and Climate}

Natural environment and climate factors could usually determine the architectural forms. And the ones in different regions are the results of suiting for the natural environment. Architectures that adapt natural environment can usually use the nature more effectively, realize low carbon and energy saving in the more special ways effectively. The conformity of architectures with environment and climate can also lead to more convenience for construction and reduce the workload and energy consumption during construction. It has become the consensus of most of architects that effective utilization of site form can reduce the work amount and effective use of wind direction and light can reduce energy consumption in architecture operation.

\section{DESIGN THINKING OF ARCHITECTURE ENERGY-SAVING PLAN}

Architecture energy saving includes meanings in two aspects. Firstly, it indicates to use architectural materials produced based on high energy consumption as less as possible, because some traditional construction materials consume a large amount of energies during the process of production, as the high-energy-consumption and highpollution construction materials. Designers are required to avoid from using those high-energy-consumption construction materials as much as possible when choosing materials. Secondly, it indicates to reduce the high energy consumption during the operation and maintenance of architectures. The unsatisfactory energy-saving effect and backward technologies of some equipments and devices in architectures will lead to the prominent problem of high energy consumption at the latter stage. In order to avoid from those problems, designers shall consider from the following aspects:

\section{A. Application of Low-energy-consumption Green Construction Materials}

Traditional construction materials and decoration materials will consume a large amount of energies during production with pollution production links and adverse influence on environment. In China's urbanization process, most of architectures apply the reinforced concrete structure; while concrete is a kind of construction material featuring high energy consumption, high pollution and high $\mathrm{CO}_{2}$ emission. Each $1 \mathrm{~m}^{2}$ of reinforced concrete structure will generate 300 $400 \mathrm{Kg} \mathrm{CO}_{2}$; and the removal of reinforced concrete structure will also lead to wastes unable to be treated. The inappropriate material use will bring about many of problems during the use and maintenance at the latter stage ${ }^{[2]}$. Therefore, designers are required to choose reproductive and recyclable construction materials with low pollution during production as many as possible. And the development of new materials shall pay attention to simplify the manufacturing technique and the recyclability of raw materials, to realize the natural ecology of architectures and form the more environmental-friendly energy-saving mode. For instance, most of architectures have stopped using solid clay bricks in walls, but the air bricks made of coal ash, which can not only save energies and materials and realize the recycled utilization of wasted materials, but also can be better in warm keeping, heat insulation and lightweight with easier production technique and no pollution to indoor environment. It is worth of stressing that the application of low-carbon green construction materials shall be effective; take the natures of materials into full consideration for the most rational design, in order to reduce the material waste and energy consumption in construction.

\section{B. Utilization of Reproductive Energies}

Reproductive energies used in architectures usually indicate solar energy, wind energy, terrestrial heat, natural light energy and other natural energies, which are featured clearness, free environmental pollution and exhaustlessness compared to other energies. For instance, the widely-used solar energy has the following advantages: a. Exhaustlessness. Solar energy is infinite and can save normal energies; b. Cleanness and environmental protection. It can reduce the carbon emission and the damage to environment. Therefore, there have been a lot of newly developed mature products based on the widely-applied solar energy in modern architectures for more ideal effect of energy saving and energy consumption. At present, solar panels are widely paved above the roofs of buildings to build small-scale power stations, which can provide residents with electric power for daily life; and solar heat collection devices are equipped within walls to provide buildings with constant temperature. For another example, designers shall try to apply the natural lighting design, to reduce the waste of artificial lighting energies in daytime. Traditionally, designers usually design windows of various shapes for lighting and introduce more natural light into the indoor space through changing windows' direction, areas and depths. Yet along with technology development, designers are more and more initiative to use advanced methods in lighting design: light pipes, light-guide fibers and other materials are used to enhance the indoor light intensity and take full advantage of natural light energy. The thorough application of reproductive energies can not only take shape a sound awareness of energy saving, but also motivate the development of more and more energy-saving technologies and products. 


\section{Application of New Energy-saving Technologies}

Various methods and approaches are needed to realize low carbon and energy saving of architectures. Therefore, the development and application of new technologies of energy saving is the key element. At present, new-type warm-keeping systems, roofing systems and energy-saving window and door systems based on new materials applied in architectures today are new technologies being developed targeting at energy saving. For instance, walls of traditional architectures only function for segmentation or bearing. However, based on the low carbon and energy saving concept of modern architecture, wall has become new factor for energy saving. And walls constructed based on new technologies and materials can absorb energies. For example, Domat/Ems ecological energysaving walls for residential buildings in Switzerland, which applies TWD composite material, can stop het radiation in summer and absorb solar energy in winter, featuring high environmental adaptability [2]. The wide application of new technologies has optimized the methods to use energies and make energy consumption in architecture spaces be controlled at rational levels.

\section{Energy-saving System Design \& Energy Structure Optimization}

Architectures in different regions have different demands on energies during the operation process, with different levels of energy consumption. Therefore, designers shall design targeted energy-saving systems responding to different energy-consumption features to optimize the energy composition and structure. For instance, northern and southern parts of China have different demands on energies. The southern China features muggy summer, leading to a higher usage amount of electric power for air conditioners, so that designers shall design the newly-type energy-saving systems or apply low energy-consumption electrical equipments and fully develop solar energy and earth cooling resource to improve the single energy structure, when designing architectures in southern part. And the northern China consumes a large amount of coal resource for heating, leading to massive emission of pollutants and dusts, so that designers shall apply newly replaceable energies to reduce pollution. For instance, natural gas and other clean energies can be applied to solve the pollutant emission problems brought about by coal combustion; and designers could research on the warmkeeping technologies of architecture walls to maintain the great gas tightness and heat preservation to reduce heat loss. For instance, they can make special designs for doors and windows for effective energy saving. The external windows and doors are the weakest parts for energy loss in residential buildings, the energy consumption of which accounts for a large proportion in the overall residential energy consumption, with a heat transfer loss rate as $1 / 3$ and cold air infiltration rate as $1 / 3$. Therefore, under the conditions of ensuring sunlight, lighting, ventilation and viewing, designers shall try to reduce the areas windows and doors to upgrade their gas tightness, reduce the cold air infiltration, upgrade the warm-keeping property of external windows and doors, decrease the heat transfer rate of external windows and doors, upgrade the gas tightness of external windows through controlling the ratio of windows and walls and improve the warm-keeping property of materials used for residential windows and doors, in order to achieve the target of energy saving[3].

\section{CONCLUSION}

Architecture is not only the integration of techniques and arts, but also the ecological spatial environment. Designers shall utilize technologies and aesthetics for construction, while considering the ecological effect of architecture and its energy consumption and environmental influence. Therefore, we shall constantly maintain the design concept of low carbon and energy saving; formulated related policies; adjust the industrial structure of architecture; upgrade people's awareness on low carbon and energy saving; promote the development of new technologies and materials; strengthen the sustainable development mode of low carbon and energy saving, in order to treat the construction of our survival space with a more comprehensive and rational attitude and solve various problems emerging in energy-saving architecture design and create a more harmonious living environment.

\section{REFERENCES}

[1] Zheng Yuan. Thinking \& Research on Issues Related to Architecture Energy-saving Design [J]. China Housing Facilities, 2009 (4):52-54.

[2] Zhang Xichen. Responding Strategies of Architecture Design under Low Carbon Concept [J]. Urban Development Research, 2010(7): 45-51.

[3] Zhao Gang. Construction Energy Saving and Energy-saving Design [J]. Sci-Tech Information Development \& Economy, 2005 (7): 147-148. 